\title{
The Prevailing Origin of Psychological Problems in Young People: A Dissociation from the Future
}

\author{
Simon A Moss (Correspondence Author) \\ School of Psychological and Clinical Sciences, Charles Darwin University \\ Ellengowan Dr, Casuarina \\ NT 0810, Australia \\ E-mail: simon.moss@cdu.edu.au
}

Samuel G. Wilson

Swinburne Leadership Institute, Swinburne University

Received: December 12, 2014 Accepted: January 13, 2015 Published: March 26, 2015

doi:10.5296/iss.v3i1.6768

URL: http://dx.doi.org/10.5296/iss.v3i1.6768

\begin{abstract}
Relative to young people several decades ago, young people in industrialized societies today are more likely to experience mood disorders, adopt an external locus of control, violate social norms, and exhibit signs of narcissism. This paper formulates a theory to explain the ultimate source of these problems: a sense of dissociation from the future. Compared with young individuals before the 1970s, young individuals now are embedded in a social environment characterized by unstable roles, status, skills, and reputation. Accordingly, young people today feel their identity in the future may diverge considerably from their identity now. According to socioemotional selectivity, psychological connectedness, and meaning maintenance theory, this dissociation from the future is likely to explain many of the characteristic problems of younger generations today. A set of social policies is recommended that could override this dissociation and thus resolve an array of issues simultaneously.
\end{abstract}

Keywords: consumerism, generations, meaning, narcissism, wellbeing 


\section{Introduction}

Relative to young people several decades ago, young people in Western, industrialized societies today are more likely to experience mood disorders (Twenge, 2000, Twenge \& Campbell, 2008), violate social norms (Twenge \& Im, 2007), and exhibit signs of narcissism (Twenge, Konrath, Foster, Campbell, \& Bushman, 2008). In addition, they tend to ascribe their failures and shortcomings to undercurrents they could not control, such as the ineptitude of other people (Twenge, Zhang, \& Im, 2004). This paper introduces a model that explains the evolution of these trends over time.

According to this perspective, because of the inexorable flux that epitomizes modern capitalism, the roles of individuals and the skills that are valued shift erratically over time (Sennett, 2006). Consequently, people cannot readily envisage their life-such as their responsibilities, goals, interests, or values-in the future (Bartels \& Urminsky, 2011; Ersner-Hershfield, Garton, Ballard, Samanez-Larkin, \& Knutson, 2009). Because of this dissociation from the future, individuals are not as motivated to develop skills, knowledge, networks and other provisions that could be valuable later in life. They are unwilling to sacrifice their immediate mood to cultivate these resources (Carstensen, 1995; Fung \& Carstensen, 2004). Ultimately, this mindset impairs resilience, incites impulsive behavior, and evokes biased conclusions, manifesting as anxiety, depression, defiance, narcissism, and many other concerns.

\section{Trends in the Psychological Wellbeing of Younger Individuals}

Many studies have shown that depression, as well as increases in many other psychological disorders, have surged over the twentieth century (see James, 2008), even after controlling memory and response biases (e.g., Klerman \& Weissman, 1989; Robins \& Regier, 1991). That is, even after their mood state, inclination to label minor episodes as abnormal, and the duration between the episodes and diagnosis are controlled, these differences across time persist (e.g., Lewinsohn, Rohde, Seeley, \& Fischer, 1993).

Epidemiological studies also corroborate these contentions. For example, only 1 to $2 \%$ of Americans born before 1915, and living during the Great Wars, was diagnosed with major depression. In the 1990s, some scholars maintain this rate exceeded 20\% (Lewinsohn et al., 1993).

This increase in psychological disorders seems to be especially prevalent in younger individuals. Younger people today-especially individuals in their teens and twenties - seem to exhibit more manifestations of mental illness than younger people in previous decades, particularly in industrialized nations (Twenge, 2006; Twenge \& Campbell, 2008; Twenge, Gentile, DeWall, Ma, Lacefield, \& Schurtz, 2010). To substantiate this contention, researchers typically identify all the studies that have administered a particular scale, such as a measure of self-esteem, to a specific constituency, usually undergraduate students. The researchers then examine whether the mean of this measure, as reported in these studies, varies over time. This procedure, called cross-temporal meta-analysis (see also Twenge, 2001; Twenge \& Campbell, 2001, 2002), has shown that anxiety (Twenge, 2000), depression 
(Twenge \& Campbell, 2008), and narcissism (Twenge, Konrath, et al., 2008) have increased over time, whereas social conformity has decreased over time (Twenge \& Im, 2007). Furthermore, locus of control has shifted from internal to external (Twenge et al., 2004).

These findings cannot be readily ascribed to biases in self report. To illustrate, Twenge et al (2010) subjected the Minnesota Multiphasic Personality Inventory to cross-temporal meta-analysis. Even after responses to the lie and defensiveness scales were controlled, depression and other clinical scales were appreciably elevated in younger generations today relative to younger generations five or more decades ago. The effect sizes were large: These generations diverged by more than one standard deviation on some measures (Twenge et al., 2010).

\section{Previous Accounts of These Trends}

Twenge et al. (2010) argue that most of the psychological problems that young people experience today, such as depression, anxiety, and narcissism, can be ascribed to the culture of materialism, consumerism, and individualism (for similar perspectives, see Eckersley \& Dear, 2002; James, 2008; Kasser, 2002; Myers, 2000; Slosar, 2009). In this culture, individuals often define themselves by their possessions. These individuals often purchase goods, or seek experiences, that are not essential to their survival but differentiate themselves from other people, striving to ascend an intangible hierarchy. Consistent with this perspective, Twenge, Campbell, and Freeman (2012) showed that younger generations are more likely than older generations to prioritize money, image, and fame over community needs, relationships, and self-acceptance.

As proponents of goal contents theory (Vansteenkiste, Niemiec, \& Soenens, 2010), a subdivision of self-determination theory (Deci \& Ryan, 2008), have shown, the pursuit of these goods and materials is negatively related to wellbeing (Kasser \& Ahuvia, 2002). In particular, luxury possessions and other purchases seldom fulfill the core needs of individuals, such as the formation of relationships, the development of competence, and the experience of autonomy (Deci \& Ryan, 2008). As experimental studies show, if these needs remain unfulfilled, the wellbeing of individuals tends to diminish (Sheldon \& Filak, 2008).

This account offers key insights into the sociocultural environment that influences the incidence of mental illness but, nevertheless, is arguably incomplete. First, this pursuit of possessions and status, called extrinsic motivation (Deci \& Ryan, 1985), may be a consequence, not a cause, of the apparent decline in psychological wellbeing observed in industrialized societies. Sivanathan and Pettit (2010), for example, showed that individuals become more concerned with these motives, such as acquiring prestigious brands, after they feel threatened. In contrast, events that reinforce a sense of integrity, such as reflections about a significant personal value (Koole, Smeets, van Knippenberg, \& Dijksterhuis, 2006), tend to mitigate this predilection towards prestigious brands (Sivanathan and Pettit, 2010).

Second, even if this pursuit of possessions and status does incite the range of problems that characterize younger individuals today, scholars still need to explain why people are more inclined to adopt this extrinsic motivation today. Until the origin of this consumerism and 
individualism is clarified, practitioners cannot implement practices or formulate policies that stem this decline in mental health. That is, rampant consumerism and unbridled materialism may percolate unabated. To resolve these limitations, this paper explains how the major trends of modern society may incite both extrinsic motivations as well as all the gamut of problems that have become more common in younger individuals today. This account will be called the model of sustained strivings.

\section{Key Criteria}

To explain the increase in extrinsic motivation, mood disorders, and other problems in younger individuals today, an exemplary theory should fulfill two key criteria. First, a suitable theory should not allude to specific, circumscribed, and localized changes in society, but rather to global, latent trends that encompass and integrate a multitude of specific developments. Theories that are confined to localized changes would not be able to explain the persistence of these trends over several decades (e.g., Twenge et al., 2012). To fulfill this criterion, the model of sustained strivings revolves around the emerging trends of modern capitalism, as characterized by Galbraith (1994), Judt (2010), Reich (2009), Saul (2005), Sennett (2006), and other scholars.

Second, this theory must characterize the nexus that connects these global and latent trends in society to the affective and cognitive states of individuals. That is, the interface between systemic characteristics of Western industrialized societies and psychological processes must be characterized. The notion of psychological connectedness (Bartels \& Rips, 2010) and the theory of socio-emotional selectivity (Carstensen, 1993, 1995) are invoked to satisfy this criterion.

\section{The Fuzziness of the Future}

From the late nineteenth century until the 1970s, progressive taxation, government subsidies, and other policies gradually eroded the inequalities that had permeated Western societies (Judt, 2011). After the Second World War in particular, strong unions, combined with collective bargaining and welfare provisions, cultivated a period of equality, stability, and order (Sennett, 1999).

As the 1970s faded, however, the governments of the United States and Britain diverged from the Keynesian consensus that prevailed after the war (James, 2008). Specifically, the Bretton Woods system - the system of regulations and institutions that regulated the international monetary system after the Second World War-had collapsed (Frum, 2000). In contrast to The Netherlands, Germany, and France in which the provisions of government support was sustained, the United States and Britain, coupled with Australia and New Zealand, embraced deregulation and free market ideologies, as government support dissipated (Albert, 1993; see, also Baumol, Litan, \& Schramm, 2007).

Considerable research attests to the significant economic and sociocultural changes since the 1970s, especially but not exclusively in Anglo-American countries (e.g., Galbraith, 1994; Judt, 2010; Sennett, 2006; Reich, 2008). These scholars conclude that many of the institutions and policies that were established after the Second World War, designed to 
promote equality, stability, and order, were dismantled after the 1970s.

\section{Instability of roles}

Two key changes were especially consequential. First, after the Bretton Woods system collapsed, money and other capital could be transferred across the globe expeditiously (Mason \& Asher, 1973). Second, because of improvements in communication technology, information about companies in other regions, integral to international investment, could be accessed readily (Sassen, 1998).

These two changes, perhaps in concert with other cultural developments, transformed the socioeconomic landscape. In particular, rather than invest in companies that may grow slowly but surely over an extended period, investors began to shift their attention more to abrupt increases in share prices (Sassen, 1998). To fulfill this objective, these investors frequently redistributed their capital across companies (Sennett, 2006). Investment in shares became an increasingly complex endeavor, demanding considerable expertise (Harrison, 1994), and these activities were primarily confined to enormous financial institutions, including merchant banks.

These powerful institutions began to dominate the management of companies (Crutchley, Jensen, Jahera Jr., \& Raymond, 1999). Because these shareholders coveted instant surges in share prices, companies did not strive to evolve and to develop gradually and progressively. Instead, they attempted to exploit every opportunity that emerged (Sassen, 1998). These organizations began to respond swiftly, and perhaps impetuously, to recent, and sometimes fleeting, changes in the market (Hamel \& Prahalad, 1996). Products, services, brands, and processes were frequently refined or even transformed, and previous endeavors were often abandoned hastily.

In this volatile environment, the strategies, values, objectives, and activities of organizations tended to change abruptly and unpredictably (e.g., Robinson, Kraatz, \& Rousseau, 1994). To respond efficiently and adeptly to fluctuating demands, downsizing was rife, the composition of teams and departments changed incessantly, and many temporary contracts superseded permanent roles (Lawler, 2005; Sennett, 1999). Middle managers were especially likely to be retrenched (Salin, 2003). Rather than gradually ascend the corporate ladder, people frequently relocated to other departments, organizations, or even nations to secure attractive jobs (Sennett, 2006). This culture of flux and instability in jobs even infiltrated to the public sector, smaller organizations, and society in general (Sennett, 2006).

\subsection{Vulnerability of Status}

Because of the fluctuating values, objectives, and activities of organizations, the status or standing of employees could also change abruptly and unexpectedly (Standing, 2011). Knowledge, skills, abilities, networks, and other qualities that were valued at one time might be dismissed days later (Sennett, 2006). In the midst of downsizing and restructuring of teams, individuals could no longer depend on their official title to maintain their standing. The exponential advances in technology merely amplified this obsolescence (see Kurzweil, 1999). 
Consequently, employees needed to frequently demonstrate both their potential to adjust and the utility of their capabilities. They often competed to secure limited positions. Consistent with this account, studies reveal that many employees, ranging from medical practitioners to accountants, are now more likely than in previous decades to adopt a competitive rather than collaborative orientation (e.g., Bell \& Fay, 1997; see also Salin, 2003). The status and remuneration of employees, therefore, became increasingly vulnerable (Frank, 1995).

\subsection{Superficial Knowledge and Skills}

To maintain their status, or even a job, employees needed to show they can learn skills rapidly to accommodate fluctuating demands (Standing, 2011). Because of this fixation with flexibility, employees were not encouraged to craft, cultivate, and refine their skills gradually and progressively (Sennett, 2006). Instead, they felt obliged to develop skills rapidly, and therefore superficially, rather than gradually and extensively. They might, for example, need to operate complex software one month and then engage in fieldwork the next month.

\subsection{Product Differentiation}

As the passion to craft and cultivate skills waned, organizations could not as readily differentiate themselves on quality. Rather than depend on quality, organizations needed to cultivate another source of differentiation: image and reputation. The performance, and even the appearance, of cars did not vary appreciably across the manufacturers; yet the various brands evoked different emotions and attitudes (Sennett, 2006). Yet, unlike the quality of goods and services, the image and reputation of organizations can plummet unpredictably, in response to isolated events. This emphasis on image and reputation, therefore, merely amplified the volatility of organizations and thus magnified the instability of roles, the vulnerability of status, and the importance of flexibility.

\section{The Implications of Modern Capitalism}

The first column of Table 1 outlines the four prevailing features of modern capitalism, as delineated by Sennett (2006). The second column of this table indicates how each of these features may diminish the likelihood that individuals feel their identity now-their values, goals, and interests, for example - is likely to overlap with their identity ten years later.

First, because the roles and setting of employees now change unpredictably, people recognize their goals, aspirations, responsibilities, values, or even interests may shift dramatically in the future. They recognize their life may transform appreciably. When individuals feel their life in ten years may not be similar to their life now, they feel dissociated, rather than connected, to the future (Hershfield, Cohen, \& Thompson, 2012). Indeed, to prime this connection with the future, some researchers instruct participants to consider how their life now may be similar to the life in ten years (Hershfield et al., 2012).

Second, if the status and standing of employees could shift unexpectedly, individuals are aware their remuneration, and therefore their resources, may vary markedly. When their status diminishes, individuals are not as likely to identify with their immediate group; they do not feel they belong (for a review, see Huo, Binning, \& Molina, 2010). Consequently, if 
people feel their status is vulnerable, they recognize their social identity may change over the next decade. When people feel their social identity may change, they feel dislocated from the future; that is, they are not as concerned about the future consequences of their actions (Bartels \& Urminsky, 2011).

Third, given that individuals in modern societies do not often craft or refine their skills over time, but instead may be assigned tasks they have never tried before, people cannot imagine which activities they may undertake in the future. They do not know, for example, whether they will use a computer or interact with customers. Their images of the future, therefore, are devoid of detail and hazy rather than vivid. These hazy images of the future are not processed fluently or rapidly (Leboe \& Ansons, 2006). Interestingly, when images of the future are not processed fluently, individuals assume that existing trends will change (Huang, Song, \& Bargh, 2011). They feel their life in the future will diverge considerably from their life now.

Finally, because the image and reputation of people and their organizations are vulnerable, the self-esteem of individuals may shift erratically. In particular, according to the sociometer theory, self-esteem can be conceptualized as an innate barometer that enables people to predict whether they may be excluded or rejected (Leary, 1999). If people feel their image and reputation could wane, they feel they may be excluded or rejected, compromising their self-esteem (Leary, Haupt, Strausser, \& Chokel, 1998; Leary, Tambor, Terdal, \& Downs, 1995). These decrements and variations in self-esteem tend to undermine self-clarity - the extent to which individuals are certain of their qualities and feel these attributes are compatible with each other and consistent over time (Campbell, 1990). In short, when people feel their image or reputation is fragile, they are not as certain about their immediate or future attributes and capabilities.

Table 1. The association between four characteristics of modern capitalism and a sense of connection to the future

\begin{tabular}{ll}
\hline Prevailing Features of Modern Capitalism & Impact on Connection to the Future \\
\hline The role, employer, and even location of & $\begin{array}{l}\text { Individuals feel their goals, values, and } \\
\text { employees can change erratically }\end{array}$ \\
$\begin{array}{l}\text { interests will be dissimilar in the future } \\
\text { The status or standing of employees can shift } \\
\text { Inexpectedly }\end{array}$ & $\begin{array}{l}\text { change in the future } \\
\text { The future activities of individuals seem hazy }\end{array}$ \\
$\begin{array}{l}\text { Employees develop skills rapidly and } \\
\text { superficially rather than hone their craft }\end{array}$ & $\begin{array}{l}\text { and, therefore, are assumed to be different to } \\
\text { their activities now }\end{array}$ \\
$\begin{array}{l}\text { Image and reputation may be valued over } \\
\text { objectives indices of quality and suitability }\end{array}$ & \begin{tabular}{l} 
of their attributes and capabilities. \\
\hline
\end{tabular}
\end{tabular}

\section{The Consequences of Discontinuity with the Future}

In short, since the 1970 s, because of the trends that epitomize modern capitalism, young 
individuals have become increasingly likely to perceive their life now as dislocated from their life in the future. According to the model of sustained strivings, this dissociation with the future could underpin the consumerism, anxiety, depression, narcissism, external locus of control, and defiance that is more prevalent in younger individuals today than younger individuals several decades ago.

\subsection{The Motivation to Develop and the Likelihood of Materialism}

If people feel their identity now, including their goals, values, interests, status, and attributes, will be entirely different to their identity in the future, they tend to be more indulgent (Bartels \& Urminsky, 2011). That is, they are reluctant to sacrifice their interests now to assist their future identity - an identity that seems unfamiliar, like a stranger (Bartels \& Rips, 2010). They do not really value the success or failure of this future instantiation of themselves.

In contrast, when people feel a sense of connection with the future, they are motivated to develop knowledge, skills, abilities, networks, or other resources that could be useful in several decades (Carstensen, Isaacowitz, \& Charles, 1999; Charles \& Carstensen, 2004). As research shows, even their motivation to accrue savings has been shown to increase (Ersner-Hershfield et al., 2009).

Research verifies that a connection to the future inspires individuals to develop their knowledge, skills, and abilities. When leaders promulgate a vivid and compelling vision of the future, for example, employees are more likely to adopt a learning orientation, in which they strive to acquire capabilities rather than to outperform other people (Coad \& Berry, 1998).

This motivation to develop expertise has been shown to facilitate the formation of relationships. For example, when people strive to enhance their capabilities, rather than to outperform other individuals, they establish rapport effectively (Sasaki \& Vorauer, 2010) and trust other people readily (Janssen \& Van Yperen, 2004). This capacity of individuals to establish trusting relationships, and the concomitant decline in loneliness, has been shown to be negatively associated with materialism (Norris, Lambert, Dewall, \& Fincham, 2012). Presumably, after individuals establish trusting relationships, their need to purchase goods diminishes; that is, they do not need possessions to supplant actual relationships (Norris et al., 2012). In contrast, if individuals cannot establish trusting relationships, they develop strong attachments to possessions instead, arguably to forge a sense of security (for evidence, see Keefer, Landau, Rothschild, \& Sullivan, 2012).

Therefore, when people feel dislocated from their future, their motivation to develop resources and networks tends to decline, impeding the formation of trusting relationships and priming the need to purchase goods. Materialism tends to escalate, potentially manifesting as consumerism.

\subsection{Emotional Regulation and Wellbeing}

A connection to the future - and the corresponding motivation to develop expertise - might not only foster a sense of security and contain materialism but also enhance resilience and 
prevent anxiety or depression (cf., Wang \& Takeuchi, 2007). Specifically, as research shows, people sometimes perceive stressful events, such as negative feedback, as a challenge or opportunity to develop (Alter, Aronson, Darley, Rodriguez, \& Ruble, 2010). While they adopt this mindset, stressful events tend to increase their levels of adrenaline and their heart rate as well as dilate their blood vessels, without raising their blood pressure or cortisol levels appreciably (Blascovich, Mendes, Hunter, Lickel, \& Kowai-Bell, 2001; Tomaka, Blascovich, Kelsey, \& Leitten, 1993). These physiological responses manifest as a feeling of excitement and challenge instead of threat or anxiety (Blascovich, 1992; Tomaka et al., 1993).

In contrast, people sometimes perceive stressful events as a threat to their perception of themselves. While they adopt this mindset, stressful events tend to increase their levels of cortisol and heart rate but do not dilate their vessels (Blascovich, 1992; Blascovich \& Mendes, 2000; Kirby \& Wright, 2003). Instead, their blood pressure escalates, experienced as a sense of threat and anxiety (Blascovich, 1992; Tomaka et al., 1993). Consequently, when people feel dislocated from their future, anxiety is more likely to prevail.

A sense of connection with the future may not only diminish anxiety but is likely to alleviate depression as well. When individuals feel their life now is pertinent to their future goals, they perceive their immediate activities as meaningful rather than futile. They become more attuned to the significant and rewarding possibilities they may enjoy in the future. These possibilities, therefore, seem more vivid and thus plausible (cf., Reber \& Schwartz, 1999), translating to feelings of optimism (Ho, Cheung, \& Cheung, 2010). That is, people believe they can more readily achieve their aspirations, and these beliefs have been shown to alleviate feelings of dejection and sadness (Scott \& Hara, 1993; Higgins, 1999; Strauman, 1989). Indeed, many studies have shown that optimism can alleviate depression (e.g., Shapira \& Mongrain, 2010).

Many other mechanisms could underpin the association between a connection to the future and emotional regulation. For example, when people feel connected to the future, they are not as inclined to prioritize their immediate needs over their future consequences (Bartels \& Urminsky, 2011). They do not attach significant value to immediate, but resolvable, problems (Ersner-Hershfield et al., 2009). They may accept immediate unease or distress, and this acceptance has been shown to curb anxiety (e.g., Forman, Herbert, Moitra, Yeo mans, and Geller, 2007), depression (e.g., Zettle \& Rains, 1989), as well as many related mental health problems (e.g., Keough, Timpano, Riccardi, \& Schmidt, 2010). Regardless of the precise mechanisms, research confirms that individuals who feel their life now is meaningful to their future have been shown to report greater wellbeing (Ho et al., 2010).

\subsection{Biased Assumptions, Narcissism, and Locus of Control}

This connection to the future not only inspires people to acquire capabilities and to embrace challenges, but may also diminish the likelihood or magnitude of cognitive biases. That is, when individuals feel connected to the future and are motivated to develop their expertise, they embrace information or experiences that diverge from their preconceptions or preferences, such as negative feedback. In contrast, if people feel dislocated from the future and unmotivated to develop their expertise, they may dismiss information that deviates from 
their preconceptions or preferences; their assumptions and conclusions, therefore, are often biased (Heine, Proulx, \& Vohs, 2006).

Indeed, as proponents of the meaning maintenance model (Heine et al., 2006) have demonstrated, when individuals perceive their environment or activities now as incoherent or meaningless to the future, four constellations of bias tend to surface. First, when people feel their environment is incoherent and meaningless, they tend to overestimate the extent to which the world is fair and just (Heine et al., 2006). They may, for example, denigrate marginal communities, such as prostitutes (Randles, Proulx, \& Heine, 2010). Once they denigrate these communities, they can sustain the assumption that life is fair and just (cf, Lerner, 1980). They can, to some extent, convince themselves that such marginalized communities deserve this fate. Presumably, after they feel the world is fair and just, this sense of incoherence abates (Proulx \& Heine, 2008).

Second, if the environment seems incoherent and meaningless, people also demonstrate a need for closure (Heine et al., 2006; Van Tongreen \& Green, 2010). Specifically, to override their sense of incoherence, they strive to contrive a feeling of certainty. They may, for example, reach conclusions prematurely, without due consideration (Webster \& Kruglanski, 1994). They may shun also unpredictable or unfamiliar settings (Webster \& Kruglanski, 1994). Indeed, they even seem to recognize patterns in pictures that actually comprise random dots (Proulx \& Heine, 2009).

Third, whenever the environment seems incoherent and meaningless, people are inclined to assume their achievements will be valued eternally (Van Tongreen \& Green, 2010). They endorse statements like "My achievements will be valued after I die" (Van Tongreen \& Green, 2010). Arguably, this bias reinforces the assumption that values in society are durable and, therefore, enables individuals to feel their identity in the future will overlap with their identity now (see Proulx \& Heine, 2006).

Finally, if people feel the environment seems incoherent and meaningless, individuals tend to inflate their self-esteem (Heine et al, 2006; Van Tongreen \& Green, 2010). They overestimate their competence and capabilities. This self-esteem may enable people to feel they can achieve their aspirations in the future; consequently, they feel they will not need to relinquish these goals and thus feel connected to the future.

These biases could explain some of the problems that characterize many younger people today, such as narcissism. In particular, according to some researchers, narcissism primarily reflects the strong motivation of some individuals to inflate their capabilities and inhibit their limitations (Konrath, Bushman, \& Campbell, 2006). Yet, suppressed limitations tend to be stored in an activated state (cf., Wegner, 1994) and, therefore, bias the perceptions and interpretations of individuals. For example, neutral comments are more likely to be perceived as personal affronts, manifesting as defensive or aggressive behavior, common in people who report narcissism (Raskin \& Terry, 1988). Therefore, if people feel dislocated from the future, and thus tend to inflate the durability of their achievements and the magnitude of their capabilities, they are likely to exhibit the qualities that epitomize narcissism. 


\section{Macrothink}

Issues in Social Science

ISSN 2329-521X

2015, Vol. 3, No. 1

This narcissism may also translate into an external locus of control, especially if individuals also experience a need for closure. That is, if people overestimate their capabilities, they may feel they have not received the recognition and rewards they deserve. They feel entitled to greater riches, a hallmark of narcissism (Campbell, Bonacci, \& Shelton, 2004). To explain this discrepancy between their capabilities and the recognition they receive, individuals need to feel that other forces, such as misfortune or corruption, have impeded their success. They need to adopt an external locus of control. Consistent with this assumption that a dissociation from the future can ultimately foster an external locus of control, people who feel committed to their future aspirations, called a promotion focus, are more likely to demonstrate an internal locus of control (Molden \& Higgins, 2008).

\subsection{Impulsive Behavior and Violations of Standards}

Finally, a sense of connection to the future may bias not only cognition but may shape behavior as well. Specifically, if people feel connected to their future identity, they may sacrifice their immediate pleasure to develop resources that could be useful in the future. They will, therefore, resist acts that evoke pleasant emotions now but regret later-acts like unhealthy eating, substance abuse, compulsive buying, and problem gambling. They will not, therefore, yield to urges or temptations that violate social norms and standards may be penalized in the future. Instead, they are more likely to comply with the conventions and expectations of their society.

Certainly, research corroborates the possibility that a discontinuity with the future coincides with impulsive behaviors. If people feel dissociated from the future, they are not as inclined to consider the consequences of their actions (Hershfield et al, 2012). This inattention to future consequences is positively associated with impulsive behaviors, such as smoking (Piko, Luszczynska, Gibbons, \& Tekozel, 2005) and limited exercise (Ouellette, Hessling, Gibbons, Reis-Bergan, \& Gerrard, 2005).

\section{Conclusion}

To reiterate, since the 1970s, the strategies and operations of organizations have become increasingly erratic. Because of these trends, the roles, status, activities, and image of individuals is especially vulnerable to change. Individuals are more likely to feel their identity in the future - their goals, values, and interests, for example - may diverge markedly from their identity now. As specified in the first column of Table 2, when individuals experience this dissociation, their motivation to develop expertise declines, their capacity to regulate negative emotions wanes, their assumptions are more likely to biased, and their behavior is more likely to be impulsive. These tendencies increase the likelihood of consumerism, anxiety, depression, and narcissism as well as evoke an external locus of control and violations of social norms. These problems, each of which appear in the second column of Table 2, are more prevalent in younger individuals today compared to younger individuals several decades ago. 
Table 2. The consequences of dissociation with the future and the implications of these consequences to younger individuals

\begin{tabular}{ll}
\hline Consequences of a Dissociation with the Future & $\begin{array}{l}\text { Implications of these } \\
\text { Consequences }\end{array}$ \\
\hline $\begin{array}{l}\text { Individuals are not as motivated to develop expertise, impeding } \\
\text { relationships }\end{array}$ & $\begin{array}{l}\text { Materialism and } \\
\text { consumerism } \\
\text { Anxiety and } \\
\text { depression }\end{array}$ \\
$\begin{array}{l}\text { Individuals cannot regulate negative emotions effectively } \\
\text { to which the world is just, they reach premature conclusions, and } \\
\text { they overestimate the longevity and quality of their contributions } \\
\text { Individuals yield to immediate temptations }\end{array}$ & $\begin{array}{l}\text { external locus of } \\
\text { control } \\
\text { Violation of social } \\
\text { norms and standards }\end{array}$ \\
\hline
\end{tabular}

\subsection{Limitations}

This article imputes many problems in younger individuals to a dissociation with the future. Nevertheless, several boundaries and caveats need to be considered.

First, these dynamics may be especially pronounced in Anglo-American nations. Although the features of modern capitalism has manifested in all developed nations, the instability of modern organizations is particularly apparent in the United States, the United Kingdom, Canada, Australia, and New Zealand in contrast to Western European countries (Sennett, 2006). This disparity may explain the observation, derived from the WHO World Mental Health Survey Consortium and other studies, that mental disorders are twice as high in Anglo-American countries than in mainland Western European countries (James, 2008). For example, the annual prevalence of mental disorders-defined as anxiety disorders, mood disorders, impulse-control disorders and substance use disorders-was about $26.4 \%$ in the United States but only $8.2 \%$ in Italy, 9.2\% in Germany, 9.2\% in Spain, and 12\% in Belgium (Demyttenaere et al. 2004).

Second, the model of sustained strivings was primarily formulated to explain the problems in younger individuals today. Whether the same principles apply to older individuals today compared to older individuals several decades ago has not been established. Cross-temporal meta-analysis have primarily been confined to university students, most of whom are younger (e.g., Twenge et al., 2010).

Arguably, older individuals today may not be as susceptible to modern capitalism as younger individuals today. Specifically, older individuals were more likely to have experienced stable economic conditions. During these stable times, they may have developed more adaptive skills to regulate emotions. For example, they may have learnt that stressful events can be regarded as challenges - a tendency that may have persisted even as society became more unstable. 


\subsection{Implications}

The model of sustained strivings implies that many problems that permeate modern society, from anxiety and depression to narcissism and social defiance, can be, at least partly, ascribed to a dissociation from the future. Consequently, attempts to redress this dissociation could improve the mental health and functioning of younger individuals.

Many initiatives could be introduced to redress this dissociation. For example, in many nations, students are not permitted to embark on a specific career unless they receive adequate grades. Consequently, before they receive their grades, they cannot envisage their future vividly; they are likely to feel dislocated from their future goals, evoking a cycle of problems.

To curb this problem, universities could potentially construct units or courses in which the marginal costs are zero, such as online courses with multiple choice questions. Students should be permitted to enroll in these units, regardless of their grades. Once these complete enough of these units, they should then be eligible for expensive units that are not available to everyone. This scheme, as well as many other innovations, may enable individuals to envisage their future more precisely and solve a range of rampant problems.

\section{References}

Albert, M. (1993). Capitalism against capitalism (translated by P. Haviland). London: Whurr.

Bartels, D. M., \& Rips, L. J. (2010). Psychological connectedness and intertemporal choice. Journal of Experimental Psychology-General, 139, 49-69. http://dx.doi.org/10.1037 /a0018062

Bartels, D. M., \& Urminsky, O. (2011). On intertemporal selfishness: How the perceived instability of identity underlies impatient consumption. Journal of Consumer Research, 38, 182-198. http//d x.doi.org/10.1086/658339

Baumol, W., Litan, R., \& Schramm, C. (2007). Good capitalism, bad capitalism, and the economics of growth and prosperity. Newhaven and London: Yale University Press.

Bell, J. D. \& Fay, M. T. (1997). A longitudinal study of the attitudes of the medical profession towards competition and advertising. International Journal of Advertising, 17, 349-336.

Blascovich, J. (1992). A biopsychosocial approach to arousal regulation. Journal of Social and Clinical Psychology, 11, 213-227.

Blascovich, J., \& Mendes, W. B. (2000). Challenge and threat appraisals: The role of affective cues. In J. Forgas (Ed.), Feeling and thinking: The role of affect in social cognition (pp. 59-82). Cambridge UK: Cambridge University Press.

Blascovich, J., Mendes, W. B., Hunter, S. B., Lickel, B., \& Kowai-Bell, N. (2001). Perceiver threat in social interactions with stigmatized others. Journal of Personality and Social Psychology, 80, 253-267. http//dx.doi.org/ 10.1037//0022-3514.80.2.253

Campbell, J. D. (1990). Self-esteem and clarity of the self-concept. Journal of Personality 
and Social Psychology, 59, 538-549.

Campbell, W., Bonacci, A. M., \& Shelton, J. (2004). Psychological entitlement: Interpersonal consequences and validation of a self-report measure. Journal of Personality Assessment, 83, $29-45$.

Carstensen, L. L. (1993). Motivation for social contact across the life span: A theory of socioemotional selectivity. In J. E. Jacobs (Ed.), Nebraska symposium on motivation: 1992, Developmental perspectives on motivation (Vol. 40, pp. 209-254). Lincoln: University of Nebraska Press.

Carstensen, L. L. (1995). Evidence for a life-span theory of socioemotional selectivity. Current Directions in Psychological Science, 4, 151-156.

Carstensen, L. L., Isaacowitz, D. M., \& Charles, S. T. (1999). Taking time serious ly: A theory of socioemotional selectivity. American Psychologist, 54, 165-181. http://dx.doi.org /10.1037//0003-066X.54.3.165

Charles, S. T., \& Carstensen, L. L. (2004). A life-span view of emotional functioning in adulthood and old age. In P. Costa (Ed.), Recent advances in psychology and aging (Vol. 15, pp. 133-162). Amsterdam: Elsevier.

Coad, A. F., \& Berry, A. J. (1998). Transformational leadership and learning orientation. Leadership \& Organization, 19, 164-172.

Crutchley, C. E., Jensen, M. R. H., Jahera Jr., J. S., \& Raymond, J. E. (1999). Agency problems and the simultaneity of financial decision making: The role of institutional ownership. International Review of Financial Analysis, 8, 177-197.

Deci, E. L., \& Ryan, R. M. (2008). Facilitating optimal motivation and psychological well-being across life's domains. Canadian Psychology, 49, 14-23. http://dx.doi.org /10.1037/0708-5591.49.1.14

Deci, E., \& Ryan, R. (1985). Intrinsic motivation and self-determination in human behavior. New York: Plenum Press.

Demyttenaere, K. et al. (2004). Prevalence, severity, and unmet need for treatment of mental disorder in the World Health Organization World Mental Health Surveys. Journal of the American Medical Association, 291, 2581-2590.

Eckersley, R., \& Dear, K. (2002). Cultural correlates of youth suicide. Social Science and Medicine, 55, 1891-1904.

Ersner-Hershfield, H., Garton, M. T., Ballard, K., Samanez-Larkin, G. R., \& Knutson, B. (2009). Don't stop thinking about tomorrow: Individual differences in future self-continuity account for saving. Judgment and Decision Making, 4, 280-286.

Forman, E. M., Herbert, J. D., Moitra, E., Yeomans, P. D., \& Geller, P. A. (2007). A randomized controlled effectiveness trial of acceptance and commitment therapy and cognitive therapy for anxiety and depression. Behavior Modification, 31, 772-799. 
http://dx.doi.org/10.1177/0145445507302202

Frank, R. H. (1995). The winner-take-all-society. How more and more Americans complete for ever fewer and bigger prizes, encouraging economic waste, income inequality, and impoverished cultural life. New York: Free Press.

Frum, D. (2000). How we got here: The '70s. New York: Basic Books.

Fung, H. H., \& Carstensen, L. L. (2004). Motivational changes in response to blocked goals and foreshortened time: Testing alternatives for socioemotional selectivity theory. Psychology and Aging, 19, 68-78. http//d x.doi.org/10.1037/0882-7974.19.1.68

Galbraith, J. K. (1994). A journey through economic time: A first hand view. Boston, MA: Houghton Mifflin.

Hamel, G., \& Prahalad, C. (1996). Competing in the new economy: Managing out of bounds. Strategic Management Journal, 17, 237-242.

Harrison, B. (1994). The dark side of flexible production. Technology Review, 97, 38-45.

Heine, S. J., Proulx, T., \& Vohs, K. D. (2006). Meaning maintenance model: On the coherence of human motivations. Personality and Social Psychology Review, 10, 88-110.

Hershfield, H. E., Cohen, T. R., \& Thompson, L. (2012). Short horizons and tempting situations: Lack of continuity to our future selves leads to unethical decision making and behavior. Organizational Behavior and Human Decision Processes, 117, 298-310. http://dx.doi.org/10.1016/j.obhdp.2011.11.00

Higgins, E. T. (1999). When do self-discrepancies have specific relations to emotions? The second-generation question of Tangney, Niedenthal, Covert, and Barlow (1998). Journal of Personality and Social Psychology, 77, 1313-1317.

Ho, M. Y., Cheung, F. M., \& Cheung, S. F. (2010). The role of meaning in life and optimism in promoting well-being. Personality and Individual Differences, 48, 658-663. http://dx.doi.org/10.1016/j.paid.2010.01.008

Huang, J. Y., Song, H., \& Bargh, J. A. (2011). Smooth trajectories travel farther into the future: Perceptual fluency effects on prediction of trend continuation. Journal of Experimental Social Psychology, 47, 506-508. http://dx.doi.org/10.1016/j.jesp.2010.12.002

Huo, Y. J., Binning, K. R., \& Molina, L. E. (2010). Testing an integrative model of respect: Implications for social engagement and well-being. Personality and Social Psychology Bulletin, 36, 2001-212. http://dx.doi.org/10.1177/0146167209356787

James, O. (2008). The selfish capitalist: Origins of affluenza. London: Vermillion.

Janssen, O., \& Van Yperen, N. W. (2004). Employees' goal orientations, the quality of leader-member exchange, and the outcomes of job performance and job satisfaction. Academy of Management Journal, 47, 368-384. http://dx.doi.org/10.2307/20159587

Judt, T. (2010). Ill fares the land. New York: The Penguin Press. 
Kasser, T. (2002). The high price of materialism. Cambridge, MA: MIT Press.

Kasser, T., \& Ahuvia, A. (2002). Materialistic values and well-being in business students. European Journal of Social Psychology, 32, 137-146.

Keefer, L. A., Landau, M. J., Rothschild, Z. K., \& Sullivan, D. (2012). Attachment to objects as compensation for close others' perceived unreliability. Journal of Experimental Social Psychology, 48, 912-917. http://dx.doi.org/10.1016/j.jesp.2012.02.007

Keough, M. E., Timpano, K. R., Riccardi, C. J., \& Schmidt, N. B. (2010). Suppressing the white bears interacts with anxiety sensitivity in the prediction of mood and anxiety symptoms. Personality and Individual Differences, 49, 408-413. http://dx.doi.org/10.1016 /j.paid.2010.04.008

Kirby, L. D., \& Wright, R. A. (2003). Cardiovascular correlates of challenge and threat appraisals: A critical examination of the Biopsychosocial Analysis. Personality and Social Psychology Bulletin, 7, 216-233. http://dx.doi.org/10.1207/S15327957PSPR0703_02

Klerman, G. L., \& Weissman, M. M. (1989). Increasing rates of depression. Journal of the American Medical Association, 261, 2229-2235.

Konrath, S., Bushman, B. J., \& Campbell, W. K. (2006). Attenuating the link between threatened egotism and aggression. Psychological Science, 17, 995-1001. http://dx.doi.org /10.1111/j.1467-9280.2006.01818.x

Koole, S. L., Smeets, K., van Knippenberg, A., \& Dijksterhuis, A. (2006). The cessation of rumination through self-affirmation. Journal of Personality and Social Psychology, 77, 111-125. http://dx.doi.org/10.1037/0022-3514.77.1.111

Kurzweil, R. (1999). The age of spiritual machines. Viking.

Lawler, E. E. (2005). Creating high performance organizations. Asia Pacific Journal of Human Resources, 43, 10-17.

Leary, M. R. (1999). Making sense of self-esteem. Current Directions in Psychological Science, 8, 32-35.

Leary, M. R., Haupt, A. L., Strausser, K. S., \& Chokel, J. T. (1998). Calibrating the sociometer: The relationship between interpersonal appraisals and state self-esteem. Journal of Personality and Social Psychology, 74, 1290-1299.

Leary, M. R., Tambor, E. S., Terdal, S. K., \& Downs, D. L. (1995). Self-esteem as an interpersonal monitor: The sociometer hypothesis. Journal of Personality and Social Psychology, 68, 518-530.

Leboe, J. P., \& Ansons, T. (2006). On misattributing good remembering to a happy past: An investigation into the cognitive roots of nostalgia. Emotion, 6, 596-610. http://dx.doi.org /10.1037/1528-3542.6.4.596

Lerner, M. J. (1980). The belief in a just world: A fundamental delusion. New York: Plenum 
Press.

Lewinsohn, P., Rohde, P., Seeley, J., \& Fischer, S. (1993). Age-cohort changes in the lifetime occurrence of depression and other mental disorders. Journal of Abnormal Psychology, 102, 110-120.

Mason, E. S., \& Asher, R. E. (1973). The World Bank since Bretton Woods. Washington, D.C.: The Brookings Institution.

Molden, D. C., \& Higgins, E. T. (2008). How preferences for eager versus vigilant judgment strategies affect self-serving conclusions. Journal of Experimental Social Psychology, 44, 1219-1228.

Myers, D. G. (2000). The American paradox: Spiritual hunger in an age of plenty. New Haven, CT: Yale University Press.

Norris, J. I., Lambert, N. M., Dewall, C. N., \& Fincham, F. D. (2012). Can't buy me love?: Anxious attachment and materialistic values. Personality and Individual Differences, 53, 666-669. http $/ / d x . d o i . o r g / 10.1016 / j . p a i d .2012 .05 .009$

Ouellette, J. A., Hessling, R., Gibbons, F. X., Reis-Bergan, M., \& Gerrard, M. (2005). Using images to increase exercise behavior: Prototypes versus possible selves. Personality and Social Psychology Bulletin, 31, 610-620. http://dx.doi.org/10.1177/0146167204271589

Piko, B. F., Luszczynska, A., Gibbons, F. X., Tekozel, M. (2005). A culture-based study of personal and social influences of adolescent smoking. European Journal of Public Health, 15, 393-398. http://dx.doi.org/10.1093/eurpub/cki008

Proulx, T., \& Heine, S. J. (2006). Death and black diamonds: Meaning, mortality, and the Meaning Maintenance Model. Psychological Inquiry, 17, 309-318.

Proulx, T., \& Heine, S. J. (2008). The case of the transmogrifying experimenter: Affirmation of a moral schema following implicit change detection. Psychological Science, 19, 1294-1300. http://dx.doi.org/10.1111/j.1467-9280.2008.02238.x

Proulx, T., \& Heine, S. J. (2009). Connections from Kafka: Exposure to meaning threats improves implicit learning of an artificial grammar. Psychological Science, 20, 1125-1131. http://dx.doi.org/10.1111/j.1467-9280.2009.02414.x

Randles, D., Proulx, T., \& Heine, S. J. (2010). Turn-frogs and careful-sweaters: Non-conscious perception of incongruous word pairings provokes fluid compensation. Journal of Experimental Social Psychology, 47, 246-249. http://dx.doi.org/10.1016 /j.jesp.2010.07.020

Raskin, R., \& Terry, H. (1988). A principal-components analysis of the Narcissistic Personality Inventory and further evidence of its construct validity. Journal of Personality and Social Psychology, 54, 890-902.

Reber, R., \& Schwarz, N. (1999). Effects of perceptual fluency on judgments of truth. Consciousness \& Cognition: An International Journal, 8, 338-342. http://dx.doi.org/10.1006 
/ccog.1999.0386

Reich, R. (2009). Supercapitalism: The battle for democracy in an age of big business. London: Icon books.

Robins, L. N., \& Regier, D. A. (Eds.). (1991). Psychiatric disorders in America: The Epidemiologic Catchment Area Study. New York: Free Press.

Robinson, S., Kraatz, M., \& Rousseau, D. (1994). Changing obligations and the psychological contract: A longitudinal study. Academy of Management Journal, 37, 137-152. http://dx.doi.org/10.2307/256773

Salin, D. (2003). Ways of explaining workplace bullying: A review of enabling, motivating, and precipitating structures and processes in the work environment. Human Relations, 56, 1213-1232. http $/ /$ d x.doi.org/10.1177/00187267035610003

Sasaki, S. J., \& Vorauer, J. D. (2010). Contagious resource depletion and anxiety? Spreading effects of evaluative concern and impression formation in dyadic social interaction. Journal of Experimental Social Psychology, 46, 1011-1016. http://dx.doi.org/10.1016 /j.jesp.2010.07.003

Sassen, S. (1998). The mobility of labor and capital: A study in international investment and labor flow. Cambridge: Cambridge University Press.

Saul, J. R. (2005). The collapse of globalism: And the reinvention of the world. Camberwell, VIC: Penguin Books.

Scott, L. O., \& Hara, M. W. (1993). Self-discrepancies in clinically anxious and depressed university students. Journal of Abnormal Psychology, 102, 282-287.

Sennett, R. (2006). The culture of the new capitalism. New Haven, CT: Yale University Press.

Shapira, L. B., \& Mongrain, M. (2010). The benefits of self-compassion and optimism exercises for individuals vulnerable to depression. Journal of Positive Psychology, 5, 377-389. http://dx.doi.org/10.1080/17439760.2010.516763

Sheldon, K. M., \& Filak, V. (2008). Manipulating autonomy, competence, and relatedness in a game-learning context: New evidence that all three needs matter. British Journal of Social Psychology, 47, 267-283.

Sivanathan, N., \& Pettit, N. C. (2010). Protecting the self through consumption: Status goods as affirmational commodities. Journal of Experimental Social Psychology, 46, 564-570. http://dx.doi.org/10.1016/j.jesp.2010.01.006

Slosar, J. R. (2009). The culture of excess: How America lost self-control and why we need to redefine success. Santa Barbara, CA: Praeger.

Standing, G. (2011). The precariat: The new dangerous class. London: Bloomsbury Academic.

Strauman, T. J. (1989). Self-discrepancies in clinical depression and social phobia: Cognitive 
structures that underlie emotional disorders? Journal of Abnormal Psychology, 98, 14-22.

Tomaka, J., Blascovich, J., Kelsey, R. M., \& Leitten, C. L. (1993). Subjective, physiological, and behavioral effects of threat and challenge appraisal. Journal of Personality and Social Psychology, 65, 248-260.

Twenge, J. M. (2000). The age of anxiety? Birth cohort change in anxiety and neuroticism, 1952-1993. Journal of Personality and Social Psychology, 79, 1007-1021.

Twenge, J. M. (2001). Changes in women's assertiveness in response to status and roles: A cross-temporal meta-analysis, 1931-1993. Journal of Personality and Social Psychology, 81, 133-145.

Twenge, J. M. (2006). Generation me: Why today's young Americans are more confident, assertive, entitled--and more miserable than ever before. New York, Free Press.

Twenge, J. M., \& Campbell, S. M. (2008). Generational differences in psychological traits and their impact on the workplace. Journal of Managerial Psychology, 23, 862-877. http://dx.doi.org/10.1109/EMR.2011.5876178

Twenge, J. M., \& Campbell, W.K. (2001). Age and birth cohort differences in self-esteem: A cross-temporal meta-analysis. Personality and Social Psychology Review, 5 321-344.

Twenge, J. M., \& Campbell, W.K. (2002). Self-esteem and socioeconomic status: A meta-analytic review. Personality and Social Psychology Review, 6, 59-71.

Twenge, J. M., \& Im, C. (2007). Changes in the need for social approval, 1958-2001. Journal of Research in Personality, 41, 171-189. http://dx.doi.org/10.1016/j.jrp.2006.03.006

Twenge, J. M., \& Nolen-Hoeksema, S. (2002). Age, gender, race, socioeconomic status, and birth cohort differences on the Children's Depression Inventory: A meta-analysis. Journal of Abnormal Psychology, 111(4), 578-588. http://dx.doi.org/10.1037/0021-843X.111.4.578

Twenge, J. M., Campbell, W. K., \& Freeman, E. C. (2012). Generational differences in young adults' life goals, concern for others, and civic orientation, 1966-2009. Journal of Personality and Social Psychology, 102, 1045-1062. http://dx.doi.org/10.1037/a0027408

Twenge, J. M., Konrath, S., Foster, J. D., Campbell, W. K., \& Bushman, B. J. (2008). Egos inflating over time: A cross-temporal meta-analysis of the Narcissistic personality inventory. Journal of Personality, 76, 875-902. http://dx.doi.org/10.1111/j.1467-6494.2008.00507.x

Twenge, J. M., Zhang, L., \& Im, C. (2004). It's beyond my control: A cross-temporal meta-analysis of increasing externality in locus of control, 1960-2002. Personality and Social Psychology Review, 8, 308-319.

Twenge, J., Gentile, B., DeWall, C. N., Ma, D., Lacefield, K., \& Schurtz, D. R. (2010). Birth cohort increases in psychopathology among young Americans, 1938-2007: A cross-temporal meta-analysis of the MMPI. Clinical Psychology Review, 30, 145-154. http://dx.doi.org /10.1016/j.cpr.2009.10.005 
Van Tongreen, D., \& Green, J. D. (2010). Combating meaninglessness: On the automatic defense of meaning. Personality and Social Psychology Bulletin, 36, 1372-1384. http://dx.doi.org/10.1177/0146167210383043

Vansteenkiste, M., Niemiec, C., \& Soenens, B. (2010). The development of the five mini-theories of self-determination theory: An historical overview, emerging trends, and future directions. In T. Urdan, \& S. Karabenick (Eds.), Advances in motivation and achievement. The decade ahead (Vol. 16, pp. 105-166). UK: Emerald Publishing.

Wang, M., \& Takeuchi, R. (2007). The role of goal orientation during expatriation: A cross-sectional and longitudinal investigation. Journal of Applied Psychology, 92, 1437-1445. http://dx.doi.org/10.1037/0021-9010.92.5.1437

Webster, D. M., \& Kruglanski, A. W. (1994). Individual differences in need for cognitive closure. Journal of Personality and Social Psychology, 67, 1049-1062.

Wegner, D. M. (1994). Ironic processes of mental control. Psychological Review, 101, 34-35.

Zettle, R. D., \& Rains, J. C. (1989). Group cognitive and contextual therapies in treatment of depression. Journal of Clinical Psychology, 45, 438-445. 